\title{
Clinical Pathway for Early Diagnosis of COVID-19: Updates from Experience to Evidence-Based Practice
}

\author{
Guogang $\mathrm{Xu}^{1} \cdot$ Yongshi Yang ${ }^{2} \cdot{\text { Yingzhen } \mathrm{Du}^{1} \cdot \text { Fujun Peng }}^{3,4} \cdot$ Peng Hu ${ }^{1} \cdot$ Runsheng Wang ${ }^{1} \cdot$ Ming Yin $^{1} \cdot$ Tianzhi Li $^{1}$ • \\ Lei Tu $^{5} \cdot$ Jinlyu Sun ${ }^{2} \cdot$ Taijiao Jiang $^{3,4} \cdot$ Christopher Chang $^{6,7}$
}

Published online: 24 April 2020

(C) Springer Science+Business Media, LLC, part of Springer Nature 2020

\begin{abstract}
The COVID-19 pandemic is a significant global event in the history of infectious diseases. The SARS-CoV-2 appears to have originated from bats but is now easily transmissible among humans, primarily through droplet or direct contact. Clinical features of COVID-19 include high fever, cough, and fatigue which may progress to ARDS. Respiratory failure can occur rapidly after this. The primary laboratory findings include lymphopenia and eosinopenia. Elevated D-dimer, procalcitonin, and CRP levels may correlate with disease severity. Imaging findings include ground-glass opacities and patchy consolidation on CT scan. Mortality is higher in patients with hypertension, cardiac disease, diabetes mellitus, cancer, and COPD. Elderly patients are more susceptible to severe disease and death, while children seem to have lower rates of infection and lower mortality. Diagnostic criteria and the identification of persons under investigation have evolved as more data has emerged. However, the approach to diagnosis is still very variable from region to region, country to country, and even among different hospitals in the same city. The importance of a clinical pathway to implement the most effective and relevant diagnostic strategy is of critical importance to establish the control of this virus that is responsible for more and more deaths each day.
\end{abstract}

Keywords COVID-19 - SARS-CoV-2 - Pandemic - Acute respiratory distress syndrome - WHO - CDC - Coronavirus · Pneumonia $\cdot$ Outbreak $\cdot$ Infection $\cdot$ Quarantine $\cdot$ Virus $\cdot$ Transmission $\cdot$ Clinical pathway

Guogang Xu, Yongshi Yang, Yingzhen Du and Fujun Peng contributed equally to this work.

Lei Tu

tulei_1985@126.com

Jinlyu Sun

sunjinlv@pumch.cn

Taijiao Jiang

taijiao@ibms.pumc.edu.cn

$\triangle$ Christopher Chang

chrchang@mhs.net

1 Department of Respiratory Medicine, The Second Medical Center \& National Clinical Research Center for Geriatric Diseases, Medical College of PLA, Chinese PLA General Hospital, Beijing 100853, China

2 Department of Allergy \& Clinical Immunology, Peking Union Medical College Hospital, Peking Union Medical College \& Chinese Academy of Medical Sciences, National Clinical Research Center for Immunologic Diseases, No. 1 Shuaifuyuan Wangfujing Dongcheng District, Beijing 100730, China
3 Center for Systems Medicine, Institute of Basic Medical Sciences, Chinese Academy of Medical Sciences \& Peking Union Medical College, No. 9, Dongdan 3rd, Dongcheng District, Beijing 100005, China

4 Suzhou Institute of Systems Medicine, Suzhou 215123, Jiangsu, China

5 Division of Gastroenterology, Union Hospital, Tongji Medical College, Huazhong University of Science and Technology, Wuhan 430022, China

6 Division of Pediatric Immunology and Allergy, Joe DiMaggio Children's Hospital, 1131 N 35th Avenue, Suite 220,

Hollywood, FL 33021, USA

7 Division of Rheumatology, Allergy and Clinical Immunology, University of California, Davis, CA 95616, USA 


\section{Introduction}

In December 2019, a novel coronavirus SARS-CoV-2 first appeared in Wuhan, China, causing a serious coronavirus disease called COVID-19 [1]. Initially believed to have originated in animals, it was later shown to be able to spread from person to person [2, 3]. On January 21, 2020, the COVID-19 was classified into a category B infectious disease of high priority requiring countrywide management measures (category A management measures) in China. On January 30, WHO declared that the outbreak of SARS-CoV-2 was a Public Health Emergency of International Concern (PHEIC). As of March 26, 2020, there have been 552,943 cases of COVID-19 confirmed in 200 countries and regions, including 399,192 active cases, 25,045 deaths, and 128,706 cases recovered. On March 2, the European CDC raised the SARS-CoV-2 risk level from moderate to high. Almost the entire globe is now designated by the US CDC as under a class 3 travel advisory. On March 11, 2020, the WHO declared COVID19 a pandemic. Global travel has been severely restricted and mass quarantine measures have been implemented in almost every country.

The symptoms of COVID-19 are non-specific, ranging from asymptomatic to severe pneumonia and death. Fever and cough are the most common clinical symptoms. Abnormal chest computed tomography (CT) has been used to diagnose $67.4-88.0 \%$ cases of COVID-19, indicating that pneumonia is the most common manifestation of the disease [4-6]. Therefore, CT imaging is widely used in the early diagnosis of the disease, but chest CT may not distinguish COVID-19 from other viral pneumonias [7-9]. Nucleic acid assay, gene sequencing, and serology examination (IgM and $\mathrm{IgG}$ ) from throat swabs or blood samples have been developed to establish a pathologic diagnosis [7]. However, clinicians in Wuhan have raised the issue of high false negative rate of PCR or antibody detection [10]. Combination use of medical history, clinical manifestations, chest $\mathrm{CT}$, and the viral test has been found to have high sensitivity $(92-97 \%)[5,6]$. Based on current understanding of COVID-19, the Chinese government regularly provides an updated clinical protocol to guide screening tactics to manage COVID-19 in epidemic areas. Globally, early diagnosis of COVID-19 is still a major challenge.

\section{Methods}

\section{Search Strategy and Selection Criteria}

A search was carried out in MEDLINE, PubMed, CNKI, WanFang, SinoMed, 2019 Novel Coronavirus Resource (2019nCoVR) of China National Center for Bioinformation, and Scientific Platform for the New Coronavirus Pneumonia of China Medical Journal Network to identify published studies on the new coronavirus. Our search strategy included the terms "2019-nCoV," "2019 Novel coronavirus," "SARSCoV-2," and "COVID-19." Relevant articles published in English or Chinese were included.

\section{Discussion/Observations}

\section{Origin}

The COVID-19 breakout was initially associated with Wuhan Huanan Seafood Wholesale Market. However, 13 of the first confirmed 41 cases had no contact history with the market. Thus, the origin of SARS-CoV-2 remains to be determined $[11,12]$. Bioinformatics analysis revealed that the sequence homology was $96 \%$ between SARS-CoV-2 and Bat-CoVRaTG13 previously detected in Rhinolophus affinis from Yunnan Province, rather than the earlier SARS-CoV (sequence homology less than $80 \%$ ). Therefore, the Chinese chrysanthemum bat was speculated to be the origin of SARS-CoV-2 [13-15]. Further investigation identified that pangolin might be a potential intermediate host because the $\mathrm{S} 1$ protein of Pangolin-CoV is virtually identical to that of SARS-CoV-2. On the other hand, the genomic similarity of SARS-CoV-2 has been found to be lower compared with Pangolin-CoV than Bat-CoV-RaTG13 [16-19]. These findings suggest that further studies are required to trace intermediate hosts in the jump from bats to humans.

Although respiratory droplets and direct contact are the main routes of transmission [2, 4, 7, 20], other routes include aerosol and fecal-oral transmission (Fig. 1) [4, 21].

\section{Human-to-Human Spread}

In mid-January 2020, studies of clusters of infected family members and medical workers confirmed person-to-person transmission $[2,3,22]$. Close contact with symptomatic individuals constitutes the major risk for extensive transmission. Ongoing spread may rely on unknown transmission by asymptomatic hosts [20]. Guan et al. reported that of the $3.5 \%$ of infected patients who were identified as healthcare workers, $1.9 \%, 31.3 \%$, and $72.3 \%$ of patients had a history of contact with wildlife, recent traveled to Wuhan, and contact with people from Wuhan, respectively [4].

a) Respiratory droplets-SARS-CoV-2 is transmitted mainly via respiratory droplets $[2,4,7,20]$. When a patient coughs or sneezes, aerial droplets containing virus may be inhaled by susceptible individuals.

b) Direct contact - Guan et al. found that $71.8 \%$ of non-local residents developed COVID-19 due to contact with individuals from Wuhan [4]. More than 1800 of 2055 ( 
Fig. 1 Modes of transmission of SARS-CoV-2. The solid frames indicate confirmed modes of transmission whereas the dotted boxes have yet to be confirmed
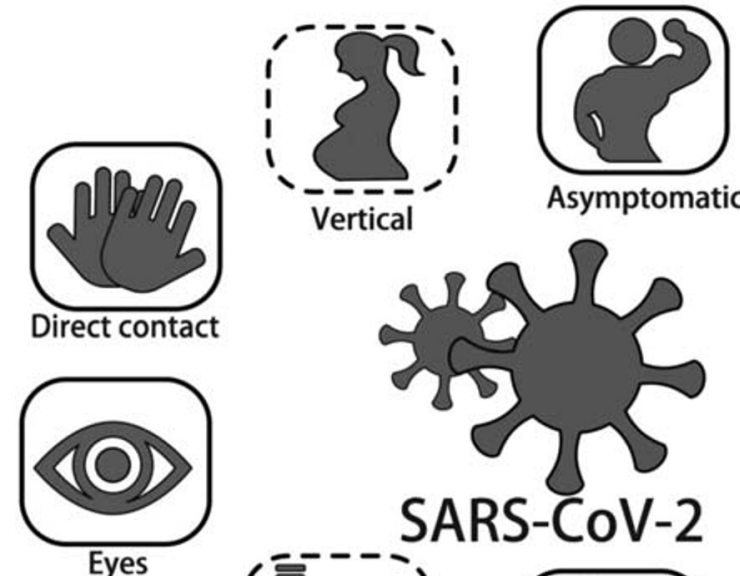

Asymptomatic
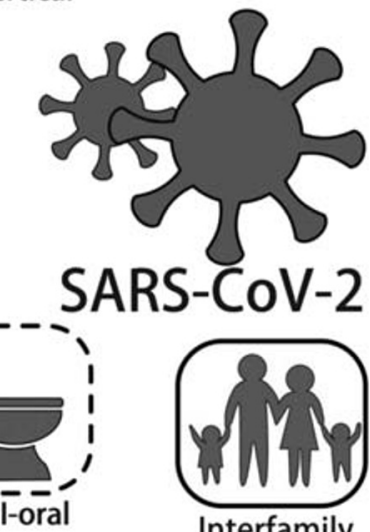

SARS-CoV-2
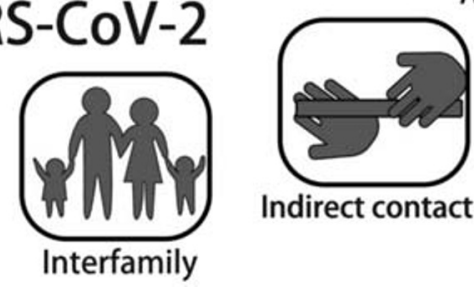

Indirect contact

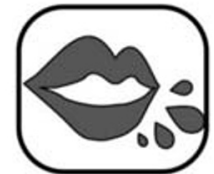

Droplets

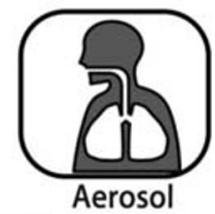

Aerosol

$88 \%$ ) medical workers with COVID-19 were in Hubei, according to reports from 475 hospitals [20].

c) Indirect contact - this occurs when droplets containing SARS-CoV-2 land on the surface of tabletops, doorknobs, telephones, and other inanimate objects. The virus is transferred from the surface to the mucous membranes by contaminated fingers touching the mouth, nose, or eyes [23]. Studies have estimated that SARS-CoV-2 can exist for up to 5 days at a temperature of $20{ }^{\circ} \mathrm{C}$ and a humidity of $40-50 \%$ and can survive for less than $48 \mathrm{~h}$ in dry air, with a reduction in viability after $2 \mathrm{~h}$ [24].

d) Asymptomatic transmission-asymptomatic infections have been reported in at least two cases with exposure history to a potentially pre-symptomatic patient who was later diagnosed with COVID-19. The virus was then transmitted to another three healthy family members $[25$, 26]. Prior to the development of symptoms, individuals may not be isolated and may constitute an important mobile viral source. This transmission contributes to the difficulties in containing the spread of the disease [27, 28].

e) Interfamilial transmission - transmission within family clusters is very common. One study reported that 78 to $85 \%$ of cases in large aggregate groups occurred due to interfamilial transmission in Sichuan and Guangdong, China [20].

f) Aerosol transmission - in a closed environment with poor ventilation, aerosols may remain airborne for $24-48 \mathrm{~h}$ and spread from several meters to dozens of meters [7, 29, 30]. However, there has been no strong evidence for aerosol transmission. The WHO also deemed that this route requires further investigation $[31,32]$.

g) Ocular transmission - it has been reported that a doctor without eye protection was infected during an inspection

in Wuhan on January 22, 2020 [33]. Further studies found that SARS-CoV-2 may be detected in the tears and conjunctival secretions of COVID-9 patients [34, 35].

h) Fecal-oral transmission - this was first reported in a COVID-19 case in the USA [21]. Subsequent studies detected SARS-CoV-2 in the feces and anal swabs of COVID-19 patients [4, 36]. Furthermore, 23.3\% of COVID-19 patients remained SARS-CoV-2 positive in feces even when the viral RNA was no longer detectable in the respiratory tract. SARS-CoV-2 has also been detected in gastric, duodenal, and rectal epithelia [37].

There is insufficient evidence to support vertical transmission as samples from neonates born to SARS-CoV-2-positive mothers have been negative [38-41]. Moreover, no viral RNA has been detected from the vaginal environment of 35 female patients, suggesting a lack of evidence for sexual transmission of SARS-CoV-2 [42].

\section{Susceptible Populations}

With the increasing number of COVID-19 cases, all individuals have a theoretical risk of contact with virus carriers [33]. Major risk factors for developing severe infection include old people and the presence of comorbidities or underlying diseases, such as hypertension, diabetes, and cardiovascular disease [4, 20, 43]. A study of 1524 cancer patients showed that they had a twofold increased risk of COVID-19 than the general population [44]. Other high-risk populations include those who are immunosuppressed due to primary or acquired immunodeficiency syndromes or those who are iatrogenically immunosuppressed. 
Pregnant women can develop COVID-19 infection [38-41]. The data on children suggests that the disease in children is less severe. In a study of 55,924 patients with COVID-19, children under the age of 18 years comprised $2.4 \%$. Of these, $2.5 \%$ had severe disease, and $0.2 \%$ were categorized as critically ill [20]. It is estimated that in China, there have been fewer than 10 deaths among individuals under the age of 30 so far [43]. Intriguingly, the pediatric patients were found through tracking close contacts of infected individuals and were not found in turn to transmit the virus to adults [20]. Healthcare personnel are at a high risk of being infected. In one study, $29 \%$ of 139 hospitalized patients were medical workers [45].

\section{Clinical Manifestations}

a) General information - according to reports from China's CDC, $51.4 \%(22,981 / 44,672)$ were male and $86.6 \%$ were aged 30-79 years [43]. The mean incubation period was 5-6 days, with a range of 1 to 14 days. The median age was 51 years (range 2 days to 100 years, interquartile range between 39 and 63 years of age) [20].

b) Symptoms - the observed symptoms of COVID-19 were generally non-specific, including fever, dry cough, fatigue, and sputum production. Some patients complained of sore throat, headache, myalgia, arthralgia, diarrhea, nasal congestion, or runny nose. In severe cases, COVID-19 presents with pneumonia, dyspnea, and/or hypoxemia occurred more than 1 week after the initial infection. Fever was the most common symptom $(91.7 \%, 411 / 448)$, followed by cough $(67.2 \%, 301 / 448)$, fatigue $(52.5 \%, 235 / 448)$, dyspnea $(45.1 \%, 178 / 395)$, sputum production $(36.1 \%, 103 / 285)$, anorexia $(29.3 \%$, $39 / 133)$, myalgia or arthralgia $(22.2 \%, 71 / 320)$, chills $(18.2 \%, 37 / 203)$, sore throat $(15.3 \%, 40 / 261)$, and headache $(11.6 \%, 39 / 337)$. The clinical manifestations of the 448 pooled severe cases are summarized in Table $1[4,11$, 45-52].

c) Severity-China's CDC has reported 44,672 cases, with $80.9 \%$ being mild or moderate cases, $13.8 \%$ severe cases, and $4.7 \%$ critical cases. The overall case-fatality rate was $2.3 \%$ and $81 \%$ of the deaths occurred in patients over 60 years of age. The mortality rate of critical cases was $49 \%$ [43].

d) Comorbidities - COVID-19 patients with comorbidities showed higher mortality. In Guan's study, 25.1\% (399/ 1590) of the confirmed cases reported having at least one comorbidity. The most common comorbidities included hypertension $(16.9 \%)$, diabetes $(8.2 \%)$, and cardiovascular diseases $(3.7 \%)$ [53]. In another study, hypertension $(39.7 \%)$, cardiovascular diseases $(22.7 \%)$, and diabetes $(19.7 \%)$ were the most common underlying diseases among 1023 deaths [43]. e) Complications - critical cases may progress rapidly to acute respiratory distress syndrome (ARDS), septic shock, metabolic acidosis, coagulation dysfunction, and even death. Among the 448 severe cases, complications were reported in 274 patients [4, 11, 45, 48]. The most common complication was pneumonia (76\%, 171/225), followed by ARDS $(34.7 \%, 95 / 274)$, acute cardiac injury $(23.8 \%, 24 / 101)$, septic shock $(11.3 \%, 25 / 222)$, and acute kidney injury $(9.5 \%, 26 / 274)$.

\section{Imaging Features}

The imaging findings of COVID-19 can be variable and change rapidly. Radiological examinations are important for early detection, monitoring, and evaluation of COVID-19 [54]. There were usually no abnormal findings at the early stage with digital radiography (DR). Therefore, CT is recommended for the early detection of subtle changes not found on DR [54]. Typical chest CT findings include peripherally distributed multifocal ground-glass opacities (GGOs) with patchy consolidations. Increasing numbers, extent, and density of GGOs on chest CT correlated with disease progression [55].

Pan et al. collected CT images from 63 confirmed COVID19 patients and found that $60.7 \%$ of the patients had more than two affected lobes. Fifty-four $(85.7 \%)$ patients had patchy or punctate GGOs, 12 (19.0\%) patients had patchy consolidation, $11(17.5 \%)$ patients had fibrous stripes, and $8(12.7 \%)$ patients had irregular solid nodules [56]. Another study comprised 51 cases, and the CT images showed pure GGOs in $77 \%$ of patients, GGOs with reticular and/or interlobular septal thickening in $75 \%$ of patients, GGOs with consolidation in $59 \%$ of patients, and pure consolidation in $55 \%$ of patients. Eighty-six percent had bilateral lung involvement, $80 \%$ had involvement of the posterior portion of the lung, and $86 \%$ had peripheral involvement [57]. In severe cases, the chest CT showed bilateral patchy shadowing in $79.2 \%$ patients, followed by GGOs in $58.4 \%$ patients, local patchy shadowing in $53.2 \%$ patients, and interstitial abnormalities in $25.4 \%$ patients [4].

A descriptive study analyzed chest CT images from 81 confirmed patients and found that COVID-19 pneumonia rapidly evolved from focal unilateral to diffuse bilateral GGOs and progressed to or co-existed with consolidations within 13 weeks [58]. The appearance of interstitial changes suggests the development of fibrosis. However, there is currently no evidence for these lung changes as irreversible fibrosis [58]. In another retrospective study on chest CT results of 21 asymptomatic patients with COVID-19, three (14\%) patients showed no GGOs or consolidation, fifteen (71\%) patients showed involvement of more than two lobes, $12(57 \%)$ 
Table 1 Demographic data, underlying diseases, and clinical manifestations of severe cases with SARS-CoV-2 infection

\begin{tabular}{|c|c|c|c|c|c|c|c|c|c|c|}
\hline Studies & $\begin{array}{l}\text { Guan et al. } \\
{[4]}\end{array}$ & $\begin{array}{l}\text { Zhang et al. } \\
{[46]}\end{array}$ & $\begin{array}{l}\text { Liu et al. } \\
\text { [47] }\end{array}$ & $\begin{array}{l}\text { Yang et al. } \\
{[48]}\end{array}$ & $\begin{array}{l}\text { Wang et al. } \\
{[45]}\end{array}$ & $\begin{array}{l}\text { Lu et al. } \\
\text { [49] }\end{array}$ & $\begin{array}{l}\text { Liu et al. } \\
{[50]}\end{array}$ & $\begin{array}{l}\text { Huang } \\
\text { et al. [11] }\end{array}$ & $\begin{array}{l}\text { Liu et al. } \\
\text { [51] }\end{array}$ & $\begin{array}{l}\text { Chen et al. } \\
\text { [52] }\end{array}$ \\
\hline ICU/severe cases & $N=173$ & $N=58$ & $N=53$ & $N=52$ & $N=36$ & $N=22$ & $N=17$ & $N=13$ & $N=13$ & $N=11$ \\
\hline $\begin{array}{l}\text { Age, mean/median } \\
\text { (range) (years) }\end{array}$ & $52(40-65)$ & $64(25-87)$ & $61(52-70)$ & 59.7 & $66(57-78)$ & NA & $56(34-73)$ & $49(41-61)$ & 59.7 & 63.9 \\
\hline \multicolumn{11}{|l|}{ Gender (no., \%) } \\
\hline Male & $100(57.8)$ & $33(56.9)$ & $28(52.8)$ & $35(67.3)$ & $22(61.1)$ & NA & $10(58.8)$ & $11(84.6)$ & $7(53.8)$ & $10(90.9)$ \\
\hline Female & $73(42.2)$ & $25(43.1)$ & $25(47.2)$ & $17(33.6)$ & $14(38.9)$ & NA & $7(41.2)$ & $2(15.4)$ & $6(46.2)$ & $1(9.1)$ \\
\hline Current smoking & $29(16.8)$ & $2(3.4)$ & NA & $2(3.8)$ & NA & NA & $2(11.8)$ & 0 & NA & NA \\
\hline \multicolumn{11}{|c|}{ Underlying diseases (no., \%) } \\
\hline Hypertension & $41(23.7)$ & $22(37.9)$ & $21(39.6)$ & NA & $21(58.3)$ & $10(45.5)$ & $6(35.3)$ & $2(15.4)$ & $5(38.5)$ & $5(45.5)$ \\
\hline Diabetes & $28(16.2)$ & $8(13.8)$ & $11(20.8)$ & $9(17.3)$ & $8(22.2)$ & $6(27.3)$ & $3(17.6)$ & $1(7.7)$ & $4(30.8)$ & $2(18.2)$ \\
\hline $\begin{array}{l}\text { Cardiovascular } \\
\text { diseases }\end{array}$ & $10(5.8)$ & $4(6.9)$ & $3(5.7)$ & $5(9.6)$ & $9(25.0)$ & $4(18.2)$ & $1(5.9)$ & $3(23.1)$ & NA & NA \\
\hline $\begin{array}{l}\text { Cerebrovascular } \\
\text { diseases }\end{array}$ & $4(2.3)$ & NA & $6(11.3)$ & $7(13.5)$ & $6(16.7)$ & $1(4.5)$ & NA & NA & NA & NA \\
\hline COPD & $6(3.5)$ & $2(3.4)$ & $2(3.8)$ & $4(7.7)$ & $3(8.3)$ & $2(9.1)$ & $3(17.6)$ & $1(7.7)$ & NA & NA \\
\hline $\begin{array}{l}\text { Chronic renal } \\
\text { diseases }\end{array}$ & $3(1.7)$ & $2(3.4)$ & $8(15.1)$ & NA & $2(5.6)$ & $2(9.1)$ & NA & NA & NA & NA \\
\hline Chronic liver diseases & NA & $4(6.9)$ & NA & NA & 0 & $1(4.5)$ & NA & 0 & NA & NA \\
\hline Cancer/malignancy & $3(1.7)$ & NA & NA & $2(3.8)$ & $4(11.1)$ & $1(4.5)$ & NA & 0 & $1(7.7)$ & NA \\
\hline \multicolumn{11}{|c|}{ Symptoms and signs (no., \%) } \\
\hline Fever & $158(91.3)$ & $51(87.9)$ & $42(79.2)$ & $51(98.1)$ & $36(100)$ & $20(90.9)$ & $17(100)$ & $13(100)$ & $13(100)$ & $10(90.9)$ \\
\hline Cough & $122(70.5)$ & $45(77.6)$ & $31(58.5)$ & $40(76.9)$ & $21(58.3)$ & $7(31.8)$ & $14(82.4)$ & $3(23.1)$ & $11(84.6)$ & $7(63.6)$ \\
\hline Fatigue & $69(39.9)$ & $39(67.2)$ & $36(67.9)$ & $18(34.6)$ & $29(80.6)$ & $7(31.8)$ & $12(70.6)$ & $7(53.8)$ & $8(61.5)$ & $10(90.9)$ \\
\hline Dyspnea & $65(37.6)$ & $24(41.4)$ & NA & $33(63.5)$ & $23(63.9)$ & $4(18.2)$ & $6(35.3)$ & $12(92.3)$ & 0 & $11(100)$ \\
\hline Sputum production & $61(35.3)$ & NA & NA & NA & $8(22.2)$ & $6(27.3)$ & $11(64.7)$ & $5(38.5)$ & $10(76.9)$ & $2(18.2)$ \\
\hline Sore throat & $23(13.3)$ & NA & NA & NA & $12(33.3)$ & 0 & $4(23.5)$ & NA & $1(7.7)$ & NA \\
\hline Myalgia or arthralgia & $30(17.3)$ & NA & NA & $7(13.5)$ & $12(33.3)$ & $2(9.1)$ & NA & $7(53.8)$ & $8(61.5)$ & $5(45.5)$ \\
\hline Headache & $26(15)$ & NA & NA & $3(5.8)$ & $3(8.3)$ & $1(4.5)$ & $3(17.6)$ & 0 & $2(15.4)$ & $1(9.1)$ \\
\hline Chills & $26(15)$ & NA & NA & NA & NA & NA & $6(35.3)$ & NA & $5(38.5)$ & $\mathrm{NA}$ \\
\hline Nausea or vomiting & $12(6.9)$ & $7(12.1)$ & NA & $2(3.8)$ & $7(19.4)$ & 0 & $2(11.8)$ & NA & $4(30.8)$ & NA \\
\hline Diarrhea & $10(5.8)$ & $9(15.5)$ & $6(11.3)$ & NA & $6(16.7)$ & 0 & $1(5.9)$ & 0 & $2(15.4)$ & $1(9.1)$ \\
\hline $\begin{array}{l}\text { Nasal } \\
\text { congestion/- } \\
\text { rhinorrhea }\end{array}$ & $6(3.5)$ & NA & NA & $3(5.8)$ & NA & 0 & NA & NA & 0 & NA \\
\hline Hemoptysis & $4(2.3)$ & NA & NA & NA & NA & NA & NA & $1(7.7)$ & NA & NA \\
\hline Chest pain & NA & NA & $3(5.7)$ & $1(1.9)$ & NA & $1(4.5)$ & 0 & NA & $5(38.5)$ & NA \\
\hline Anorexia & NA & $8(13.8)$ & NA & $\mathrm{NA}$ & $24(66.7)$ & $3(13.6)$ & $4(23.5)$ & NA & NA & NA \\
\hline
\end{tabular}

$C O P D$ chronic obstructive pulmonary diseases, $I C U$ intensive care unit, $N A$ not available

patients only had GGOs, and $6(29 \%)$ patients had GGOs with consolidation [59]. Feng et al. analyzed the CT features of 15 children with confirmed disease ( 4 to 14 years old) and found that nine patients had small nodular GGOs but six patients had no lesions [60].

\section{Laboratory Findings}

a) Diagnostic tests - reverse transcription PCR (RT-PCR) assay is widely used in the early diagnosis and monitoring of SARS-CoV-2 infections. RT-PCR was positive in 59 to $78.2 \%$ of cases $[5,6,61]$. This assay may detect the viral RNA in the early stage of clinical symptoms even with negative CT findings [62]. Gene sequencing can identify SARS-CoV-2 accurately, but the major disadvantages are that it is very timeconsuming and expensive. Gene sequencing is more important for research on the variants and origin of
SASR-CoV-2 [20]. Based on recent data in 397 cases, specific $\operatorname{IgM}$, specific $\operatorname{IgG}$, and specific $\operatorname{IgM}+$ specific IgG had a sensitivity of $18.1 \%, 6.0 \%$, and $64.5 \%$, respectively [63]. Serological assays require only $15 \mathrm{~min}$ to generate results and can be used for rapid screening in clinics [63].

b) Routine tests - in Guan's study [4] of 1099 confirmed patients, lymphopenia was present in $83.2 \%$ of the patients on admission. Changes in albumin, lactate dehydrogenase, neutrophils, and C-reactive protein (CRP) were seen in SARS-CoV-2 infections.

c) Potential biomarkers for severity - significantly higher levels of D-dimer, CRP, and procalcitonin were associated with disease severity (Table 2). Huang reported that prothrombin time and D-dimer levels on admission were higher in intensive care unit (ICU) patients than in nonICU patients [11]. Plasma concentrations of IL-2, IL-7, 
IL-10, and TNF- $\alpha$ were higher in ICU patients. In Wang's study [45], ICU patients had higher white blood cell and neutrophil counts, as well as higher levels of D-dimer, creatine kinase, and creatine. Severe patients demonstrated lymphopenia and eosinopenia. Eosinophil counts correlate positively with lymphocyte counts in severe and non-severe patients.

\section{Updates of Clinical Protocols}

On January 16, 2020, the National Health Commission (NHC) of China published the first clinical protocol based on the initial experience of several hundred of cases of novel coronavirus pneumonia. Over the past few months, an abundance of information has been acquired from the vast number of cases in China, and the data is increasing daily. Thus far, NHC has published seven versions of clinical protocols to facilitate early diagnosis and early treatment of the disease (Table 3). Figure 2 is a flowchart to help identify and assess COVID-19 that is based on these protocols and clinical experience. From February to March 2020, the mortality rate and hospital infections reported in Wuhan have decreased.

\section{Discussion}

Since the outbreak of COVID-19 pandemic, the NHC of China has successively released 7 versions of diagnosis and treatment protocols and 6 versions of prevention and control plans. Hubei, Beijing, Shanghai, Tibet, and other cities have also introduced "regional plans." As scientific evidence accumulates, these protocol updates can be based more on evidence-based practice than on empirical experience.

During the early phase of the COVID-19 outbreak, the sequencing of SARS-Cov-2 genome was published and reported to WHO [1]. Studies on the virological and epidemiological characteristics of SARS-CoV-2 are key to the containment of the virus. It has been shown that human-to-human transmission of SARS-CoV-2 occurs mainly through droplets or direct contact $[11,64]$.

The incubation period is still unknown but may be up to 14 days in most patients and as long as 24 days in several cases [4]. Gastrointestinal symptoms are uncommon, which is different from SARS-CoV [65] and MERS-CoV [66] infection. Further investigations to clarify the viral tropism of SARS-Cov-2 are important for understanding its transmission and treatment. Older patients ( $>65$ years) with comorbidities and ARDS are at an increased risk of death, and men seem more likely to be infected than women. The overall mortality rate is estimated to be $2.3 \%$ (1023 deaths among 44,762 confirmed cases of COVID-19), based on experience within
China [67]. Compared with greater than $10 \%$ mortality of SARS-CoV [68] and 35\% mortality of MERS-CoV [69], SARS-Cov-2 has a lower mortality rate but appears to be more contagious. The mortality rate may be even lower in the realworld setting once the infection has stabilized. Many studies may not include mildly ill patients who did not seek medical help. Xu's study [70] found that compared with patients infected with SARS-Cov-2 in Wuhan, the symptoms of patients in Zhejiang Province were relatively mild. There is a potential association between COVID-19 mortality and healthcare resources [71], and the mortality rate outside Wuhan may be much lower.

Some studies have postulated that the gender difference is related to the important role that both the $\mathrm{X}$ chromosomes and sex hormones play in the body's immune system [72], although the mechanism is unknown. Chest CT findings of COVID-19 include peripherally distributed multifocal ground-glass opacities (GGOs) with patchy consolidations, even in asymptomatic patients, suggesting that radiological examinations are important in the early detection, observation, and evaluation of COVID-19. Patients with laboratoryconfirmed disease without radiologic manifestations have also been reported [4].

The most common laboratory abnormality in COVID-19 patients is lymphopenia, which is more profound in severe cases. This suggests that SARS-CoV-2 may primarily attack lymphocytes, particularly T lymphocytes, as SARS-CoV does [73]. Virus particles infect cells, inducing a cytokine storm in the body, generating a series of immune responses, and causing changes in peripheral white blood cells and immune cells. Consequently, the low absolute value of lymphocytes may be used as a reference index in the diagnosis or to classify severity of SARS-CoV-2 infections [74]. At present, it is possible to predict prognosis using symptoms, signs, and imaging findings, but there are challenges. Symptoms, signs, and imaging abnormalities are often seen later in the disease course, so early detection may be difficult. In addition, once the condition deteriorates, it may lead to a vicious circle ultimately resulting in critical illness or death. The care of these patients requires a high level of medical resources, equipment, and infrastructure. Slowing the spreading of the disease helps to "flatten the curve," which helps to prevent overtaxing of healthcare systems.

Limitations of this review include the lack of uniformity between previous papers documenting the clinical manifestations of COVID-19 data derived from patients with SARSCoV-2 infection in Wuhan, China. The clinical and epidemiology characteristics summarized in studies from Wuhan may be impacted by a shortage of medical resources in Wuhan [71]. The experience in cities and countries outside of Wuhan, China, may be different as the virus has undergone mutations even since its first appearance in December 2019 [70]. There is also a lack of information regarding 


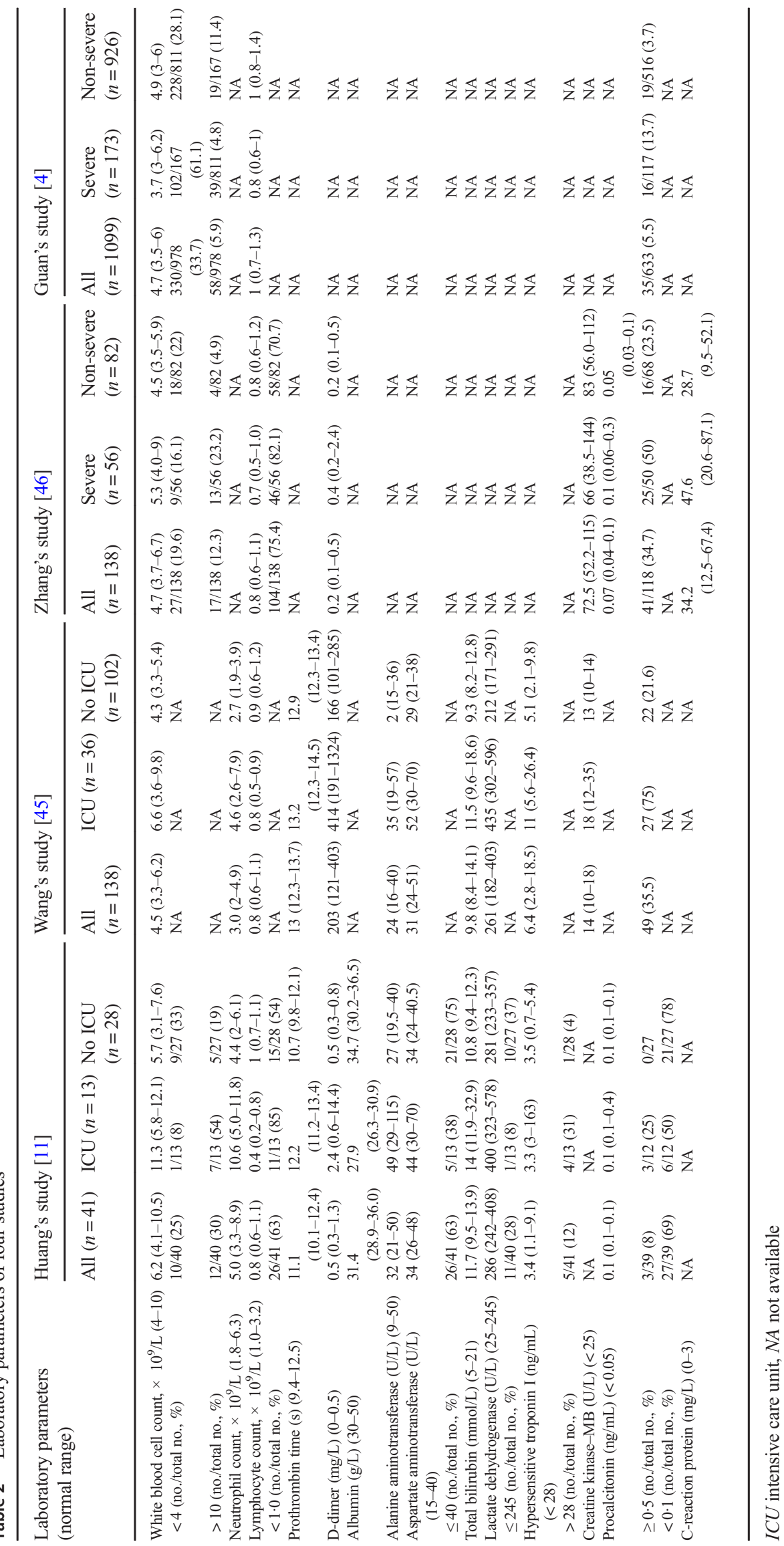


Table 3 The diagnosis criteria of suspected and confirmed cases with COVID-2019 published by NHC of PRC

\begin{tabular}{|c|c|c|c|}
\hline $\begin{array}{l}\text { Trial edition } \\
\text { (publication } \\
\text { date) }\end{array}$ & Epidemiological history & Clinical manifestations & Suspected case \\
\hline $\begin{array}{l}\text { First } \\
\qquad \begin{array}{l}\text { (January } \\
16,2020)\end{array}\end{array}$ & $\begin{array}{l}\text { Within } 2 \text { weeks before the disease } \\
\text { onset, there is a travel history or a } \\
\text { direct/indirect contact history with } \\
\text { markets in Wuhan, especially a } \\
\text { market of farm produce }\end{array}$ & $\begin{array}{l}\text { (1) Fever } \\
\text { (2) Radiographic evidence } \\
\text { of pneumonia } \\
\text { (3) Low or normal } \\
\text { leukocyte count or low } \\
\text { lymphocyte count } \\
\text { during the early stage of } \\
\text { disease } \\
\text { (4) No improvement or } \\
\text { worsening symptoms } \\
\text { after 3-5 days of anti- } \\
\text { microbial treatment per } \\
\text { standard clinical guide- } \\
\text { lines }\end{array}$ & $\begin{array}{l}\text { Anyone who satisfies the } \\
\text { epidemiological history and } \\
\text { clinical manifestations can be } \\
\text { diagnosed as a suspected case }\end{array}$ \\
\hline $\begin{array}{l}\text { Second } \\
\qquad(\text { January } \\
18,2020)\end{array}$ & $\begin{array}{l}\text { (1) Within } 2 \text { weeks before the disease } \\
\text { onset, there is a travel history or } \\
\text { living history in Wuhan } \\
\text { (2) Within } 2 \text { weeks before the disease } \\
\text { onset, there is a contact history } \\
\text { with patients who had fever or } \\
\text { respiratory symptoms from } \\
\text { Wuhan } \\
\text { (3) Clustering occurrence of cases }\end{array}$ & $\begin{array}{l}\text { (1) (2) (3) Same as above. } \\
\text { Delete (4) }\end{array}$ & Same as above \\
\hline
\end{tabular}

\section{Third}

(January

22, 2020)

Fourth

(January

27, 2020)

Fifth

(February

4, 2020)

Sixth

(February

18, 2020)
Same as above

(1) Within 2 weeks before the disease onset, there is a travel history or living history in Wuhan or other areas with local cases

(2) Within 2 weeks before the disease onset, there is a contact history with patients who had fever or respiratory symptoms from Wuhan or other areas with local cases

(3) Clustering occurrence of cases or epidemiologically associated with patients with new coronavirus pneumonia

(1) Within 14 days before the disease Supplement: (1) fever onset, there is a travel history or living history in Wuhan and its surrounding areas or other communities with cases reported

(2) Within 14 days before the disease onset, there is a contact history with patients with a positive result of the nucleic acid test of the new coronavirus

(3) Within 14 days before the disease onset, there is a contact history with patients who had fever or respiratory symptoms from Wuhan and its surrounding areas or other communities with cases reported

(4) Clustering occurrence of cases

Same as above

Same as above

Same as above

Same as above above and/or respiratory symptoms; (2) (3) same as

Supplement: anyone with a positive epidemiological history and any 2 of the clinical manifestations or anyone without definite epidemiological history but with all the clinical manifestations is considered a suspected case

Add: (2) in Hubei Province, anyone with/without an epidemiological history as well as with 2 clinical manifestations: "fever and/or respiratory symptoms, and low or normal leukocyte count or low lymphocyte count during the early stage of disease" can be considered a suspected case

Delete: the diagnosis criteria of suspected case in Hubei Province
Confirmed case

The suspected case whose gene highly homologous to the known new coronavirus by whole-genome sequencing of the virus in respiratory specimens (sputum or throat swabs) is considered a confirmed case

The suspected case with one of the following evidences is reclassified as a confirmed case:

(1) Positive results of nucleic acids of the new coronavirus by RT-PCR in respiratory specimens, such as sputum, throat swabs, and lower respiratory tract secretions

(2) The viral gene sequence is highly homologous to the known new coronavirus

Same as above

Add: blood specimens added to the RT-PCR or viral gene sequence test

The confirmed cases' diagnosis criteria are the same as above. Add: [2] In Hubei Province, suspected cases with imaging characteristics of pneumonia can be considered clinically diagnosed cases.

Delete: the diagnosis criteria of clinical diagnosis cases in Hubei Province 
Table 3 (continued)

\begin{tabular}{|c|c|c|c|c|}
\hline $\begin{array}{l}\text { Trial edition } \\
\text { (publication } \\
\text { date) }\end{array}$ & Epidemiological history & Clinical manifestations & Suspected case & Confirmed case \\
\hline $\begin{array}{l}\text { Seventh } \\
\text { (March 3, } \\
\text { 2020) }\end{array}$ & $\begin{array}{l}\text { (1) (2) (3) Same as above } \\
\text { Supplement: (4) clustering occur- } \\
\text { rence of cases (within } 2 \text { weeks, } 2 \\
\text { or more cases of fever and/or re- } \\
\text { spiratory symptoms occurred in } \\
\text { small areas such as homes, offices, } \\
\text { and school classes) }\end{array}$ & Same as above & Same as above & $\begin{array}{l}\text { (1) (2) same as above } \\
\text { Add: (3) serum new } \\
\text { coronavirus-specific IgM and IgG } \\
\text { antibodies are positive; serum new } \\
\text { coronavirus-specific IgG antibod- } \\
\text { ies change from negative to posi- } \\
\text { tive or the IgG antibodies in the } \\
\text { recovery period are } 4 \text { times or } \\
\text { higher than in the acute period }\end{array}$ \\
\hline
\end{tabular}

NHC National Health Commission, PRC People's Republic of China

communicability in the early phases of the disease in patients who have not yet manifested symptoms of COVID-19 or in asymptomatic carriers. Clinical information in some patients who have COVID-19 may be lacking as a result of failure to seek treatment in early stages with mild presentation, or a lack of awareness of the disease, although by now most people are vigilant or even hypervigilant. A shortage of detection kits can also hinder identification and confirmation of infected individuals [75]. These limitations can impact the accuracy of prior research. Lastly, because many patients are still ill in the

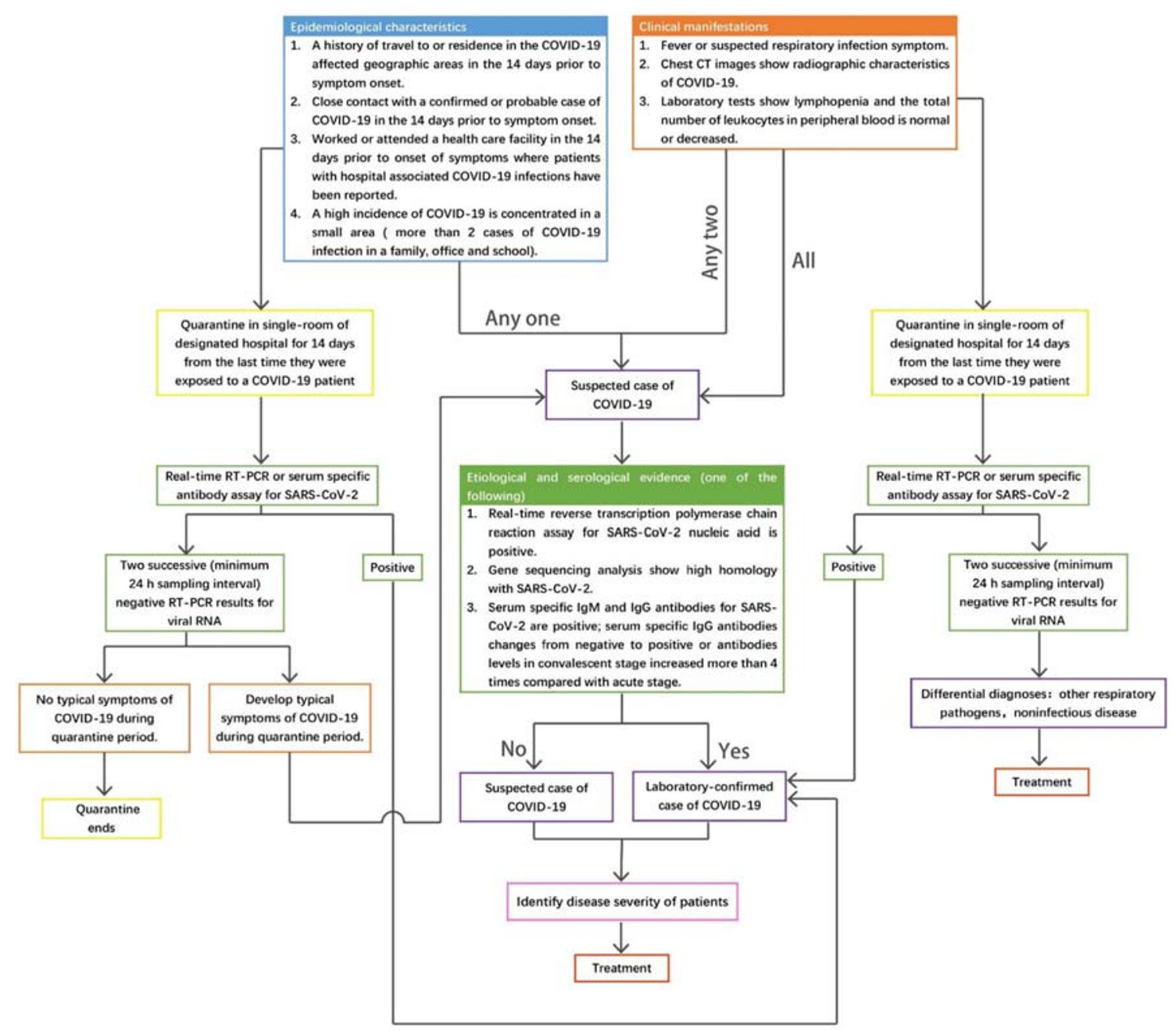

Fig. 2 A clinical pathway for the diagnosis of COVID-19. An algorithm to guide clinical decisions in the diagnosis and treatment of COVID-19 
hospital, the prognosis and the outcomes are incompletely elucidated. Most of the current studies are cross-sectional, and longitudinal studies are required.

Contributors CC, TJ, JS, and LT conceptualized the paper. GX, YY, YD, FP, and PH analyzed the data with input from LT, TL MY, and RW. YY, YD, FP, and GX wrote the initial draft with all authors providing critical feedback and edits to subsequent revisions. All authors approved the final draft of the manuscript. The corresponding authors attest that all listed authors meet authorship criteria and that no others meeting the criteria have been omitted.

Funding Information This study was partly supported by the Beijing Municipal Natural Science Foundation General Program (7192197) and the National Natural Science Foundation of China (31671371).

\section{Compliance with Ethical Standards}

Conflict of Interest The authors declare that they have no conflict of interest.

\section{References}

1. Zhu N, Zhang D, Wang W et al (2019) N Engl J Med:2020

2. Li Q, Guan X, Wu P, Wang X, Zhou L, Tong Y, Ren R, Leung KSM, Lau EHY, Wong JY, Xing X, Xiang N, Wu Y, Li C, Chen Q, Li D, Liu T, Zhao J, Liu M, Tu W, Chen C, Jin L, Yang R, Wang Q, Zhou S, Wang R, Liu H, Luo Y, Liu Y, Shao G, Li H, Tao Z, Yang Y, Deng Z, Liu B, Ma Z, Zhang Y, Shi G, Lam TTY, Wu JT, Gao GF, Cowling BJ, Yang B, Leung GM, Feng Z (2020) Early transmission dynamics in Wuhan, China, of novel coronavirus-infected pneumonia. N Engl J Med 382:1199-1207. https://doi.org/10.1056/ NEJMoa2001316

3. Chan JF, Yuan S, Kok KH et al (2020) A familial cluster of pneumonia associated with the 2019 novel coronavirus indicating person-to-person transmission: a study of a family cluster. Lancet 395:514-523

4. Guan W-J, Ni Z-Y, Hu Y, Liang WH, Ou CQ, He JX, Liu L, Shan H, Lei CL, Hui DSC, du B, Li LJ, Zeng G, Yuen KY, Chen RC, Tang CL, Wang T, Chen PY, Xiang J, Li SY, Wang JL, Liang ZJ, Peng YX, Wei L, Liu Y, Hu YH, Peng P, Wang JM, Liu JY, Chen Z, Li G, Zheng ZJ, Qiu SQ, Luo J, Ye CJ, Zhu SY, Zhong NS (2020) Clinical characteristics of coronavirus disease 2019 in China. N Engl J Med. https://doi.org/10.1056/NEJMoa2002032

5. Jiang G, Ren X, Liu Y, et al. Application and optimization of RTPCR in diagnosis of SARS-CoV-2 infection. medRxiv 2020: 2020.02.25.20027755

6. Ai T, Yang Z, Hou H et al (2020) Correlation of chest CT and RTPCR testing in coronavirus disease 2019 (COVID-19) in China: a report of 1014 cases. Radiology 200642

7. China NHCotPsRo (2020) New coronavirus pneumonia prevention and control program (seventh trial edition).(in Chinese). http:// w w w.n h c.gov.c n/ x c s/zheng c w j/ 202002 / 3b09b894ac9b4204a79db5b8912d4440.shtml

8. Kanne JP. Chest CT Findings in 2019 Novel coronavirus (2019$\mathrm{nCoV}$ ) infections from Wuhan, China: key points for the radiologist. Radiology 2020:200241

9. Pan Y, Guan H (2020) Imaging changes in patients with 2019nCov. Eur Radiol

10. Pan F, Ye T, Sun P, et al. Time course of lung changes on chest CT during recovery from 2019 novel coronavirus (COVID-19) pneumonia. Radiology 2020:200370
11. Huang C, Wang Y, Li X, et al (2020) Clinical features of patients infected with 2019 novel coronavirus in Wuhan, China. Lancet

12. Cohen J. Wuhan seafood market may not be source of novel virus spreading globally. https://www.sciencemag.org/news/2020/01/ wuhan-seafood-market-may-not-be-source-novel-virus-spreadingglobally: science

13. Lu R, Zhao X, Li J, Niu P, Yang B, Wu H, Wang W, Song H, Huang B, Zhu N, Bi Y, Ma X, Zhan F, Wang L, Hu T, Zhou H, Hu Z, Zhou W, Zhao L, Chen J, Meng Y, Wang J, Lin Y, Yuan J, Xie Z, Ma J, Liu WJ, Wang D, Xu W, Holmes EC, Gao GF, Wu G, Chen W, Shi W, Tan W (2020) Genomic characterisation and epidemiology of 2019 novel coronavirus: implications for virus origins and receptor binding. Lancet 395:565-574

14. Wu F, Zhao S, Yu B, et al (2020). A new coronavirus associated with human respiratory disease in China. Nature

15. Zhou P, Yang X-L, Wang X-G, Hu B, Zhang L, Zhang W, Si HR, Zhu Y, Li B, Huang CL, Chen HD, Chen J, Luo Y, Guo H, Jiang RD, Liu MQ, Chen Y, Shen XR, Wang X, Zheng XS, Zhao K, Chen QJ, Deng F, Liu LL, Yan B, Zhan FX, Wang YY, Xiao GF, Shi ZL (2020) A pneumonia outbreak associated with a new coronavirus of probable bat origin. Nature 579:270-273. https://doi.org/10.1038/ s41586-020-2012-7

16. Liu P, Jiang J-Z, Hua Y, et al (2020) Are pangolins the intermediate host of the 2019 novel coronavirus (2019-nCoV)?

17. Xiao K, Zhai J, Feng Y, et al Isolation and characterization of 2019nCoV-like coronavirus from Malayan Pangolins. bioRxiv 2020: 2020.02.17.951335

18. Zhang T, Wu Q, Zhang Z Pangolin homology associated with 2019nCoV. bioRxiv 2020:2020.02.19.950253

19. Li X, Zai J, Zhao Q, Nie Q, Li Y, Foley BT, Chaillon A (2020) Evolutionary history, potential intermediate animal host, and crossspecies analyses of SARS-CoV-2. J Med Virol. https://doi.org/10. 1002/jmv. 25731

20. Control CfD. China-WHO new coronavirus pneumonia (COVID19) joint inspection report. 2020. http://www.nhc.gov.cn/jkj/s3578/ 202002/87fd92510d094e4b9bad597608f5cc2c.shtml (accessed Feb.29)

21. Holshue ML, DeBolt C, Lindquist S, Lofy KH, Wiesman J, Bruce H, Spitters C, Ericson K, Wilkerson S, Tural A, Diaz G, Cohn A, Fox L, Patel A, Gerber SI, Kim L, Tong S, Lu X, Lindstrom S, Pallansch MA, Weldon WC, Biggs HM, Uyeki TM, Pillai SK, Washington State 2019-nCoV Case Investigation Team (2020) First case of 2019 novel coronavirus in the United States. N Engl J Med 382:929-936. https://doi.org/10.1056/NEJMoa2001191

22. Phan LT, Nguyen TV, Luong QC, Nguyen TV, Nguyen HT, le HQ, Nguyen TT, Cao TM, Pham QD (2020) Importation and human-tohuman transmission of a novel coronavirus in Vietnam. N Engl J Med 382(9):872-874

23. Special Expert Group for Control of the Epidemic of Novel Coronavirus Pneumonia of the Chinese Preventive Medicine A (2020) An update on the epidemiological characteristics of novel coronavirus pneumonia (COVID-19). Zhonghua Liu Xing Bing Xue Za Zhi = Zhonghua Liuxingbingxue Zazhi 41(2):139-144

24. (2020) The new coronavirus can live for up to five days in the highrisk areas of home. (in Chinese). https://wxn.qq.com/cmsid/ 20200206A0FJMS00

25. Tong Z-D, Tang A, Li K-F, Li P, Wang HL, Yi JP, Zhang YL, Yan JB (2020) Potential presymptomatic transmission of SARS-CoV-2, Zhejiang Province, China, 2020. Emerg Infect Dis 26, 26(5). https://doi.org/10.3201/eid2605.200198

26. Rothe C, Schunk M, Sothmann P, Bretzel G, Froeschl G, Wallrauch C, Zimmer T, Thiel V, Janke C, Guggemos W, Seilmaier M, Drosten C, Vollmar P, Zwirglmaier K, Zange S, Wölfel R, Hoelscher M (2020) Transmission of 2019-nCoV infection from an asymptomatic contact in Germany. N Engl J Med 382:970-971 
27. Mahase E (2020) China coronavirus: mild but infectious cases may make it hard to control outbreak, report warns. BMJ 368:m325

28. Wang F-S, Zhang C (2020) What to do next to control the 2019nCoV epidemic? Lancet (London, England) 395(10222):391-393

29. Times G (2020) Is SARS-CoV-2 spread to long distance by aerosols? (in Chinese). https://tech.huanqiu.com/article/3wyl6elmqb1

30. economics fa (2020) Travel distances of hundreds of meters! What is an aerosol?(in Chinese). https://m.21jingji.com/article/20200209/ herald/c16daaf45743f6e 479e 70517cf816744.html

31. China. NHCotPsRo (2020) What is aerosol transmission, can you still open the window after ventilation?[popular knowledge of novel coronavirus]. http://www.nhc.gov.cn/xcs/kpzs/202002/ 81b67a34e1e34154be11c30f0749dcdf.shtml (accessed Feb.10)

32. Organization (2020) WH. Question and answer on coronaviruses. www.who.int/news-room/q-a-detail/q-a-coronaviruses. (accessed feb 11)

33. China. NHCotPsRo (2020) National Health Commission Press Conference. Beijing, February 4, 2020. http://www.nhc.gov.cn/ zhuz/zbwqhg/wqhg.shtml (accessed Feb 4)

34. Xia J, Tong J, Liu M, Shen Y, Guo D (2020) Evaluation of coronavirus in tears and conjunctival secretions of patients with SARSCoV-2 infection. J Med Virol. https://doi.org/10.1002/jmv.25725

35. Sun X, Zhang X, Chen X, et al The infection evidence of SARSCOV-2 in ocular surface: a single-center cross-sectional study. medRxiv 2020:2020.02.26.20027938

36. Gao QY, Chen YX, Fang JY (2020) 2019 novel coronavirus infection and gastrointestinal tract. J Dig Dis 21:125-126. https://doi. org/10.1111/751-2980.12851

37. Xiao F, Tang M, Zheng X, et al. Evidence for gastrointestinal infection of SARS-CoV-2. medRxiv 2020: 2020.02.17.20023721

38. Huaping Zhu LW, Fang C, Peng S, Zhang L, Chang G, Xia S, Zhou W (2020) Clinical analysis of 10 neonates born to mothers with 2019-nCoV pneumonia. translational pediatrics

39. Chen H, Guo J, Wang C, Luo F, Yu X, Zhang W, Li J, Zhao D, Xu D, Gong Q, Liao J, Yang H, Hou W, Zhang Y (2020) Clinical characteristics and intrauterine vertical transmission potential of COVID-19 infection in nine pregnant women: a retrospective review of medical records. Lancet 395:809-815

40. Qiao J (2020) What are the risks of COVID-19 infection in pregnant women? Lancet

41. Rasmussen SA, Smulian JC, Lednicky JA, Wen TS, Jamieson DJ (2020) Coronavirus disease 2019 (COVID-19) and pregnancy: what obstetricians need to know. Am J Obstet Gynecol S00029378(20):30197-30196

42. Cui P, Chen Z, Wang T, et al Clinical features and sexual transmission potential of SARS-CoV-2 infected female patients: a descriptive study in Wuhan, China. medRxiv 2020:2020.02.26.20028225

43. Novel Coronavirus Pneumonia Emergency Response Epidemiology T (2020) The epidemiological characteristics of an outbreak of 2019 novel coronavirus diseases (COVID-19) in China. Zhonghua Liu Xing Bing Xue Za Zhi 41(2):145-151

44. Yu J, Ouyang W, Chua M, Xie C (2020) SARS-CoV-2 transmission in cancer patients of a tertiary hospital in Wuhan

45. Wang D, Hu B, Hu C, Zhu F, Liu X, Zhang J, Wang B, Xiang H, Cheng Z, Xiong Y, Zhao Y, Li Y, Wang X, Peng Z (2020) Clinical characteristics of 138 hospitalized patients with 2019 novel coronavirus-infected pneumonia in Wuhan, China. JAMA 323: 1061. https://doi.org/10.1001/jama.2020.1585

46. Zhang J-J, Dong X, Cao Y-Y, et al (2020) Clinical characteristics of 140 patients infected with SARS-CoV-2 in Wuhan, China. Allergy

47. Liu Y, Sun W, Li J, et al Clinical features and progression of acute respiratory distress syndrome in coronavirus disease 2019 . medRxiv 2020:2020.02.17.20024166

48. Yang X, Yu Y, Xu J et al (2020) Clinical course and outcomes of critically ill patients with SARS-CoV-2 pneumonia in Wuhan,
China: a single-centered, retrospective, observational study. Lancet Respir Med S2213-600(20):30079-30075

49. Lu H, Ai J, Shen Y, et al A descriptive study of the impact of diseases control and prevention on the epidemics dynamics and clinical features of SARS-CoV-2 outbreak in Shanghai, lessons learned for metropolis epidemics prevention. medRxiv 2020: 2020.02.19.20025031

50. Liu J, Liu Y, Xiang P, et al Neutrophil-to-lymphocyte ratio predicts severe illness patients with 2019 novel coronavirus in the early stage. medRxiv 2020:2020.02.10.20021584

51. Liu J, Li S, Liu J, et al Longitudinal characteristics of lymphocyte responses and cytokine profiles in the peripheral blood of SARSCoV-2 infected patients. medRxiv 2020:2020.02.16.20023671

52. Chen $\mathrm{G}, \mathrm{Wu} \mathrm{D}$, Guo $\mathrm{W}$, et al Clinical and immunologic features in severe and moderate forms of coronavirus disease 2019. medRxiv 2020:2020.02.16.20023903

53. Guan W-j, Liang W-h, Zhao Y, et al. Comorbidity and its impact on 1,590 patients with COVID-19 in China: a nationwide analysis. medRxiv 2020:2020.02.25.20027664

54. Association RSoCM (2020) Radiological diagnosis of new coronavirus infected pneumonitis: expert recommendation from the Chinese Society of Radiology (First edition). Chin J Radiol 2020:54

55. Zu ZY, Jiang MD, Xu PP et al (2020) Coronavirus disease 2019 (COVID-19): a perspective from China. Radiology 200490

56. Pan $Y$, Guan H, Zhou S et al (2020) Initial CT findings and temporal changes in patients with the novel coronavirus pneumonia (2019nCoV): a study of 63 patients in Wuhan. China, European Radiology

57. Song F, Shi N, Shan F, et al. Emerging coronavirus 2019-nCoV pneumonia. Radiology 2020:200274

58. Shi H, Han X, Jiang N et al (2020) Radiological findings from 81 patients with COVID-19 pneumonia in Wuhan, China: a descriptive study. Lancet Infect Dis S1473-3099(20):30086-30084

59. Chung M, Bernheim A, Mei X, et al (2020) CT imaging features of 2019 novel coronavirus (2019-nCoV). Radiology 200230

60. Feng K, Yun YX, Wang XF, et al (2020) Analysis of CT features of 15 children with 2019 novel coronavirus infection. Zhonghua Er Ke Za Zhi 58(0):E007-E

61. Fang Y, Zhang H, Xie J et al (2020) Sensitivity of chest CT for COVID-19: comparison to RT-PCR. Radiology 200432

62. Yang W, Yan F (2020) Patients with RT-PCR confirmed COVID-19 and normal chest CT. Radiology 200702

63. Li Z, Yi Y, Luo X, et al (2020) Development and clinical application of a rapid IgM-IgG combined antibody test for SARS-CoV-2 infection diagnosis. J Med Virol n/a(n/a)

64. Yu P, Zhu J, Zhang Z, Han Y, Huang L (2020) A familial cluster of infection associated with the 2019 novel coronavirus indicating potential person-to-person transmission during the incubation period. J Infect Dis

65. Leung WK, To KF, Chan PK et al (2003) Enteric involvement of severe acute respiratory syndrome-associated coronavirus infection. Gastroenterology 125(4):1011-1017

66. Assiri A, McGeer A, Perl TM, Price CS, al Rabeeah AA, Cummings DA, Alabdullatif ZN, Assad M, Almulhim A, Makhdoom H, Madani H, Alhakeem R, al-Tawfiq JA, Cotten M, Watson SJ, Kellam P, Zumla AI, Memish ZA, KSA MERS-CoV Investigation Team (2013) Hospital outbreak of Middle East respiratory syndrome coronavirus. N Engl J Med 369(5):407-416

67. Wu Z, McGoogan JM (2020) Characteristics of and important lessons from the coronavirus disease 2019 (COVID-19) outbreak in China: summary of a report of 72314 cases from the Chinese Center for Disease Control and Prevention. JAMA 323:1239

68. Ni FD, Hao SL, Yang WX (2019) Multiple signaling pathways in Sertoli cells: recent findings in spermatogenesis. Cell Death Dis 10(8):541 
69. Arabi YM, Mandourah Y, Al-Hameed F et al (2018) Corticosteroid therapy for critically ill patients with Middle East respiratory syndrome. Am J Respir Crit Care Med 197(6):757-767

70. Xu XW, Wu XX, Jiang XG et al (2020) Clinical findings in a group of patients infected with the 2019 novel coronavirus (SARS-Cov-2) outside of Wuhan, China: retrospective case series. BMJ 368:m606

71. Ji Y, Ma Z, Peppelenbosch MP, Pan Q (2020) Potential association between COVID-19 mortality and health-care resource availability. Lancet Glob Health 8:e480

72. Jaillon S, Berthenet K, Garlanda C (2019) Sexual dimorphism in innate immunity. Clin Rev Allergy Immunol 56(3):308-321

73. Liu WJ, Zhao M, Liu K, Xu K, Wong G, Tan W, Gao GF (2017) Tcell immunity of SARS-CoV: implications for vaccine development against MERS-CoV. Antivir Res 137:82-92
74. Chen N, Zhou M, Dong X, Qu J, Gong F, Han Y, Qiu Y, Wang J, Liu Y, Wei Y, Xia J', Yu T, Zhang X, Zhang L (2020) Epidemiological and clinical characteristics of 99 cases of 2019 novel coronavirus pneumonia in Wuhan, China: a descriptive study. Lancet 395:507-513

75. Biscayart C, Angeleri P, Lloveras S, Chaves T, Schlagenhauf P, Rodriguez-Morales AJ (2020) The next big threat to global health? 2019 novel coronavirus (2019-nCoV): what advice can we give to travellers? - interim recommendations January 2020, from the Latin-American society for Travel Medicine (SLAMVI). Travel Med Infect Dis 101567

Publisher's Note Springer Nature remains neutral with regard to jurisdictional claims in published maps and institutional affiliations. 